\title{
Using research on the obesity pandemic as a guide to a unified vision of nutrition
}

\author{
Barry M Popkin * \\ Department of Nutrition, School of Public Health, Carolina Population Center, University \\ of North Carolina at Chapel Hill, 123 W. Franklin Street, Chapel Hill, NC 27516-3997, USA
}

\begin{abstract}
Objective: To focus on factors that play a major role in our rapid, global nutritional changes.

Design: A range of studies are summarised: these show how an understanding of social, economic and technological change at the global, national and community levels affects diet, activity, and body composition patterns and trends. These studies are used to demonstrate the value of the key global, national, community, household and individual factors that should define the field of nutrition.

Setting: The focus is global.

Result: Large shifts have occurred in diet and in physical activity patterns particularly in the last one or two decades of the twentieth century. These changes are reflected in nutritional outcomes such as changes in average stature, body composition and morbidity. Understanding the rapidity of these changes and the underlying factors at the global, national and community levels is critical for creating a science of nutrition that can prevent disease and sustain the health and integrity of humans.

Conclusion: The vision of the nutrition field is one where scholars who work on many levels will intersect; equal weight in the nutrition profession will be provided to all dimensions as they are welcomed into the field of nutrition - particularly those that will directly or indirectly affect dietary patterns, physical activity patterns, and energetics. This vision of the nutrition field is one where scholars from a range of disciplines and perspectives meet to work together with the goal being a focus on improving nutritional status and the human condition.
\end{abstract}

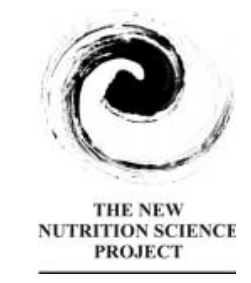

Keywords Nutrition transition Macroeconomic factors Environmental factors Physical activity Body composition
Large shifts have occurred in diet and in physical activity patterns - particularly in the last one or two decades of the twentieth century. These changes are reflected in nutritional outcomes, such as changes in average stature, body composition and morbidity. Understanding the rapidity of these changes and the underlying factors at the global, national and community levels is critical for creating a science of nutrition that can prevent disease and sustain the health and integrity of humans.

At the same time, as scholars are learning from work in the environmental and ecological arenas, the promotion of a sustainable food system needs to be fully cognisant and conscious of the interplay between creation of the food supply and the environment. The same certainly holds for the arena of physical activity, an area that must become part of the purview and focus of the nutritional field - if we are to create healthy societies. This paper focuses mainly on the nutrition field and the factors we understand as playing a major role in our rapid, global nutritional changes.

\section{Discussion}

\section{The major issues to be addressed}

In a series of papers, this author has shown some major shifts in diet, activity and body composition that have occurred across the globe. These include the following shifts:

- The structure and composition of the diets of all nations are changing rapidly. Among the key changes are:

- The world's food supply and diets have been sweetened tremendously ${ }^{1}$.

- Edible oil intake has grown very rapidly, particularly in Asia, the Middle East and Africa ${ }^{2}$.

- The energy density of diets - particularly of the lowincome world - seems to be growing rapidly ${ }^{3}$. 
The vision for our field of nutrition is one where scholars who work on many levels will intersect and interact to address complex problems. Equal weight will be given by our profession to all dimensions and these many elements will be welcomed into the field. Social, economic and behavioural aspects are as important as biological and genetic aspects. The nutrition field is envisioned as one in which scholars from a range of disciplines and perspectives meet to work together for a better world.

- The intake of animal-source foods is increasing rapidly in the low-income world ${ }^{4}$.

- Physical activity patterns across the globe are changing very rapidly. The key dimensions of this change are often ignored in the West as the focus is on leisure, and not the full set of changes taking place. Among the key changes are:

- Vast shifts in the overall allocation of market work (away from agriculture and other energy-intensive occupations) towards service sector occupations $s^{5,6}$.

- Concurrent marked reductions in the level of physical activity within each occupation ${ }^{5,7}$.

$\circ$ Changes in the types of transportation used and leisure activity patterns that reflect a rapid shift toward reduced energy expenditures ${ }^{8}$.

- Mechanisation of all home production-related activities? .

- Reduction of food preparation time by over half from 2-3 hours per day to less than an hour per day as food consumed away from home increases in the higher-income world ${ }^{10,11}$.

- Body composition shifts have led to rapid changes in global obesity and a related decline in undernutrition among adults - but less among children. The shifts in body composition include:

- Obesity is growing rapidly on a global basis and the rate of change is faster in the low-income world ${ }^{4,12}$.

- Child obesity is increasing globally; however, the levels and rates of change seem to be lagging behind those of adults ${ }^{13,14}$.

- The shift of the body composition distribution (based on body mass index) is rightward; therefore, undernutrition is declining as obesity increases ${ }^{6,15}$.

- The burden of obesity is shifting to the poor around the globe ${ }^{16,17}$.

- The shift towards obesity dominating underweight among women of childbearing age is occurring globally in both urban and rural areas ${ }^{18}$.

These changes have allowed us to understand some of the major underlying global factors. These include:

- Urbanisation has certainly accelerated the process of social and economic change linked to creating a more obesogenic environment ${ }^{5,19}$. While some new research shows that obesity is emerging in rural areas worldwide, clearly there is a confluence of factors that has made the more urbanised environments of the world to be more obesogenic. These include mass transportation systems, which replace walking and biking; mass media, which encourages a shift in diet and activity and other aspects of one's ways of life more access to Westernised and more energy-dense foods; and increased use of modern technologies in all phases of work, leisure and movement.

- Rapid income changes are very crucial $^{20,21}$. There have been very rapid increases in per capita income in countries on all continents including China, Chile, Brazil, Mexico, India and some other very large countries. The income increases have been linked with shifts towards higher energy-dense diets and reduced activity.

- Price changes are equally powerful and have been fuelled by a rapid decline in the past half century in food prices, particularly real animal-source food prices ${ }^{4,22-}$ ${ }^{24}$. The past several decades have seen major reductions in prices of beef and many other animal-source foods. For example, the real world price for $100 \mathrm{~kg}$ of beef dropped from over \$US 500 to about \$US 200.

- Technology changes and the diffusion of new technology related to activity and diet are very important ${ }^{2}$. For instance, it has been shown how the improved technology for removing edible vegetable oil from oilseeds led to improved varieties of oil seed, which then led to a revolution in the cost and availability of vegetable oils in the period from 1960 to 1989.

- Globalisation of food marketing and distribution are important in ways not yet understood ${ }^{25}$. In all regions of the world the fresh open markets of the past are being replaced by large or mega supermarkets with Carrefour, Wal-Mart and a few other global chains leading the way.

- Expansion of mass media penetration is equally powerful, but to date has not been rigorously studied, as it relates to global shifts in diet and activity and obesity. While the reach and scope of television, television advertising and all other forms of media have expanded rapidly, little is understood about the impact of these shifts on eating and activity patterns.

- Access to the types of services and infrastructure which improve dietary and physical activity patterns has 
skewed toward the rich, at least in the higher-income world and most likely in the lower-income world ${ }^{26}$.

\section{So what?}

The rapidity of change and the power of the macroeconomic forces and some community-level factors, as documented in the studies noted above, many other studies by this author, and studies by other scholars, provide us with some sense of the larger forces that truly affect our food supply. It is certainly true that individual choice, as measured and reflected in factors such as education level, play a key role ${ }^{27}$. Nevertheless, the role of education and knowledge occurs within a broader set of social, economic and technological factors that truly affect choices of food and activity patterns.

Box 1 and its figure provide some sense of the factors that interact to affect energy imbalance and obesity.

Furthermore, it is felt that we have ignored the broader environmental changes at the national and community levels and far too much of our research and thinking has been focused on individual behaviours and biology - to the neglect of these broader factors. There is a vast array of policies related to topics as diverse as food subsidies, credits and taxes, walkable communities, crime, traffic safety, building design and mass transportation that can impact diet and physical activity. Only a few examples are provided here.

Limited research has focused on analyses of the ways pricing can affect obesity and nutrition. A research model developed by Huang showed how economic factors, including own- and cross-price effects, influence food and nutrient demand ${ }^{28}$. Currently, no national food consumption surveys in the USA allow us to link food prices with these data. Similar tools in tobacco consumption have permitted important modelling to demonstrate the price elasticity of tobacco.

Within this limited research, other elements of the food system have been examined. A few studies have used food markets as venues for interventions with positive outcomes $^{29}$. Location and concentration of various food services appear to be associated with socio-economic status and racial segregation ${ }^{30,31}$. Similarly, Morland et al.

\section{Box 1 - Causal web of influence on the prevalence of obesity}

As illustrated here (Fig. 1), many factors at the national, state, community, family, clinical and individual levels affect energy imbalance and obesity. While obesity is ultimately a physiological process, many factors at each level (individual, family, clinical, community and macro) are important, and must be linked to achieve our goals. Furthermore, any change at any level aside from one at the metabolic level that affects energy utilisation or related functions must deal with the factors causing energy imbalance. Few countries have been successful in arresting or reversing the obesity epidemic in large populations and we must search for ways to address this imbalance over the life cycle.

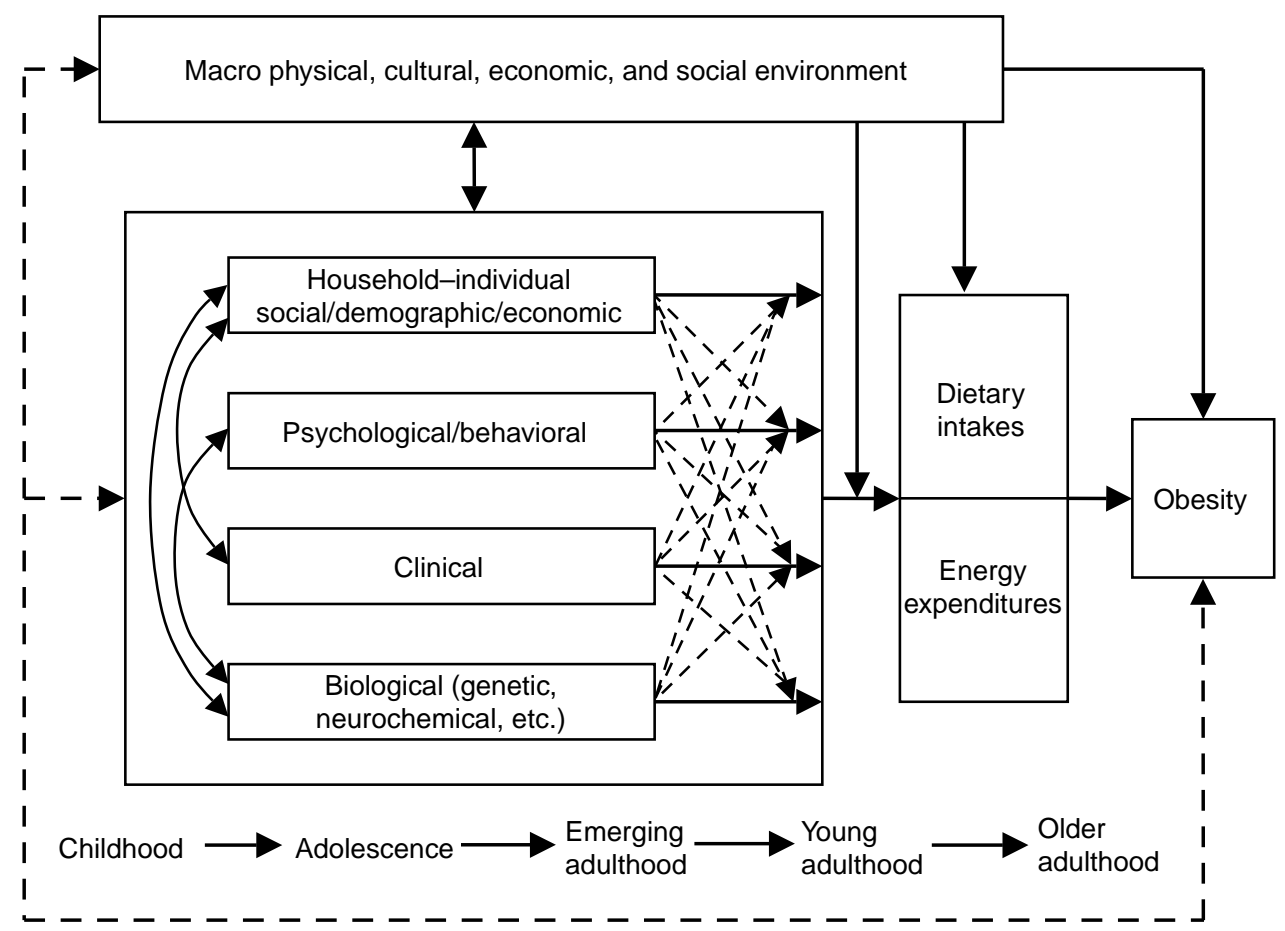

Fig. 1 Causal web of influence on the prevalence of obesity. Source: adapted from Kathleen Mullan Harris, University of North Carolina at Chapel Hill 


\section{Box 2 - Societal factors that affect obesity}

The International Obesity Task Force has created a model to delineate the major macroeconomic factors that affect obesity. It is important to emphasise that many of the major decisions set in place over the decades related to agricultural research, food trade and related factors affect the relative prices of the foodstuffs available today. Countries have designed their nation's infrastructure partially around certain models, which include an emphasis on cheap and available sugar, corn and soybeans and other grains, and oilseeds used to feed animal-source foods, and inexpensive access to beef, pork, fish, and poultry and eggs. The same can be said to exist for the development of technologies to allow us to be more sedentary. Mankind has seen a distinct focus on improving the variety and tastiness of our food and on reducing our physical effort at travel, work and leisure. Highlighted here (in Fig. 2) are some of the sectors that distinctly affect diet, activity and obesity.

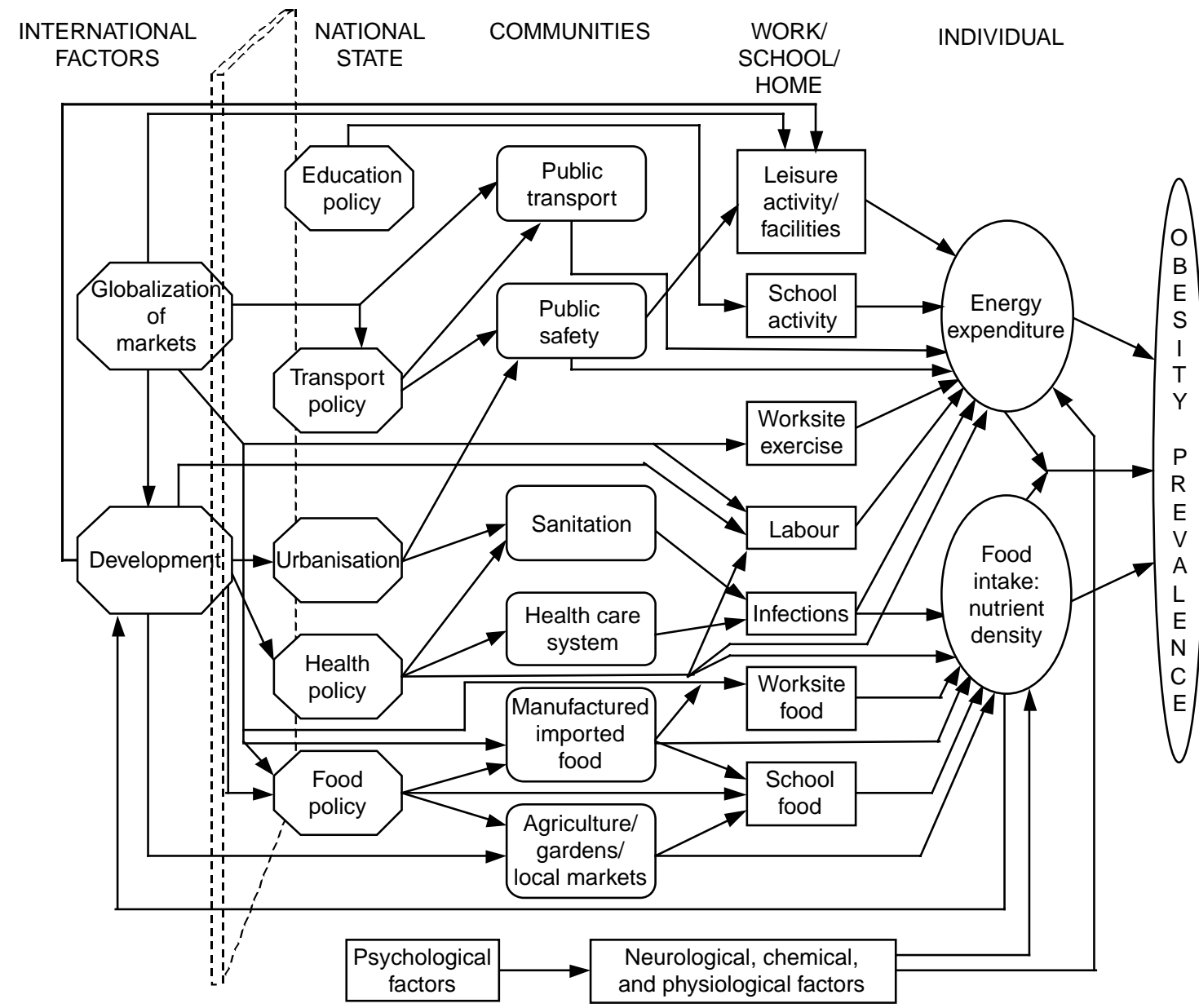

Fig. 2 Causal web of societal influences on the prevalence of obesity. Source: International Obesity Task Force website; figure developed by C Ritenbaugh, S Kumanyika, A Morabia, R Jeffrey and V Antipatis, 1999

found that the local food environment was associated with adherence to recommended dietary guidelines within racially distinct groups ${ }^{32}$. The effect on youth of environmental access to food, including vending machines, has been studied ${ }^{10,11,33,34}$. More research is needed to explain how longitudinal shifts in the food environment affect changes in eating patterns.

Researchers have examined environmental determinants such as community sports, access to home fitness equipment ${ }^{35,36}$, outdoor play space, time spent outdoors $^{37,38}$, family environments ${ }^{39}$ and exercise opportunities $^{40}$. Neighbourhood environment is related to obesity, physical activity and other health-related behaviours $^{41-45}$. Urban planners find extremely low rates of walking for transportation and few pedestrian-favourable land-use policies ${ }^{46}$. Walking/biking increases with proximity, density, connectivity ${ }^{44,45,47}$, higher population density $^{48,49}$, land-use mix, pedestrian advances (e.g. sidewalk connectivity) $)^{50-52}$ and reduced pollution ${ }^{53}$. This topic warrants additional research, replication and refinement. 
Our definition of the national and local factors should be further broadened to select the entire range of factors affecting diet, activity and energy imbalance. Before consideration of these individual behavioural and biological factors, there are many more factors at the global, national and community levels that truly play key roles in affecting food choices and activity patterns (Box 2). It is often more difficult to understand initially the macro factors and to create evidenced-based programme and policy knowledge on these factors. Minimal or no research has focused on linking in a systematic way the factors that create the food supply, food prices, and options for activity that we face daily on a global basis to the obesity changes we see.

\section{Conclusion}

So how does the world proceed to improve nutrition?

There are many national examples of limited changes that are most important for understanding some choices that we may face. Details on these are not provided here, but it is felt that much more research is needed to understand the unique characteristics that might work at the global, national and local levels.

Our field of nutrition is envisioned as one where scholars who work on many levels will intersect: equal weight will be given by our profession to all dimensions and these many elements will be welcomed into the field. Moreover, the social, economic and behavioural dimensions are as important as the biomedical ones - but these are the neglected components of the equation. The nutrition field is envisioned as one where scholars from a range of disciplines and perspectives meet to work together with the goal being a focus on these interconnected spheres.

\section{References}

1 Popkin BM, Nielsen SJ. The sweetening of the world's diet. Obesity Research 2003; 11: 1325-32.

2 Drewnowski A, Popkin BM. The nutrition transition: new trends in the global diet. Nutrition Reviews 1997; 55: 31-43.

3 Popkin BM, Lu B, Zhai F. Understanding the nutrition transition: measuring rapid dietary changes in transitional countries. Public Health Nutrition 2002; 5: 947-53.

4 Popkin BM. The nutrition transition in the developing world. Development Policy Review 2003; 21: 581-97.

5 Popkin BM. The nutrition transition and its health implications in lower income countries. Public Health Nutrition 1998; 1: 5-21.

6 Bell AC, Ge K, Popkin BM. Weight gain and its predictors in Chinese adults. International Journal of Obesity and Related Metabolic Disorders 2001; 25: 1079-86.

7 Paeratakul S, Popkin BM, Keyou G, Adair LS, Stevens J. Changes in diet and physical activity affect the body mass index of Chinese adults. International Journal of Obesity and Related Metabolic Disorders 1998; 22: 424-31.

8 Bell AC, Ge K, Popkin BM. The road to obesity or the path to prevention? Motorized transportation and obesity in China. Obesity Research 2002; 10: 277-83.
9 Lanningham-Foster L, Nysse LJ, Levine JA. Labor saved, calories lost: the energetic impact of domestic labor-saving devices. Obesity Research 2003; 11: 1178-81.

10 Nielsen SJ, Siega-Riz AM, Popkin BM. Trends in energy intake in the US between 1977 and 1996: similar shifts seen across age groups. Obesity Research 2002; 10: 370-8.

11 Nielsen SJ, Siega-Riz AM, Popkin BM. Trends in food locations and sources among adolescents and young adults. Preventive Medicine 2002; 35: 107-13.

12 Popkin BM. An overview on the nutrition transition and its health implications: the Bellagio meeting. Public Health Nutrition 2002; 5: 93-103.

13 Wang Y, Monteiro C, Popkin BM. Trends of overweight and underweight in children and adolescents in the United States, Brazil, China, and Russia. American Journal of Clinical Nutrition 2002; 75: 971-7.

14 Lobstein T, Baur L, Uauy R. Obesity in children and young people: a crisis in public health. Obesity Reviews 2004; 5(Suppl. 1): 4-97.

15 Monteiro CA, Conde WL, Popkin BM. Is obesity replacing or adding to undernutrition? Evidence from different social classes in Brazil. Public Health Nutrition 2002; 5: 105-12.

16 Monteiro CA, Conde WL, Lu B, Popkin BM. Obesity and inequities in health in the developing world. International Journal of Obesity and Related Metabolic Disorders 2004; 28 : 1181-6.

17 Monteiro CA, Moura EC, Conde WL, Popkin BM. Socioeconomic status and obesity in developing countries: a review. Bulletin of the World Health Organization 2004; 82: $940-6$.

18 Mendez MA, Monteiro CA, Popkin BM. Overweight now exceeds underweight among women in most developing countries. American Journal of Clinical Nutrition 2005; 81: 714-21.

19 Popkin BM. Urbanization, lifestyle changes and the nutrition transition. World Development 1999; 27: 1905-16.

20 Du S, Mroz TA, Zhai F, Popkin BM. Rapid income growth adversely affects diet quality in China - particularly for the poor! Social Science \& Medicine 2004; 59: 1505-15.

21 Guo X, Mroz TA, Popkin BM, Zhai F. Structural changes in the impact of income on food consumption in China, 198993. Economic Development and Cultural Change 2000; 48: 737-60.

22 Guo X, Popkin BM, Mroz TA, Zhai F. Food price policy can favorably alter macronutrient intake in China. Journal of Nutrition 1999; 129: 994-1001.

23 Delgado C, Courbois C. Trade-offs among fish, meat, and milk demand in developing countries from the 1970s to the 1990s. In: Eide A, Vassdal T, eds. Proceedings of the IXth Biennial Conference of the International Institute of Fisheries, Economics and Trade (IIFET 98), 7-11 July 1998. Tromsö: University of Tromsö, Norwegian School of Fisheries, 1998.

24 Delgado CL. Rising consumption of meat and milk in developing countries has created a new food revolution. Journal of Nutrition 2003; 133: 3907S-10S.

25 Reardon T, Timmer CP, Barrett CB, Berdegue JA. The rise of supermarkets in Africa, Asia, and Latin America. American Journal of Agricultural Economics 2003; 85: 1140-6.

26 Gordon-Larsen P, Nelson MC, Page P, Popkin BM. Inequality in the built environment underlies key health disparities in physical activity and obesity. Pediatrics 2005; in press.

27 Popkin BM, Zizza C, Siega-Riz AM. Who is leading the change? United States dietary trends 1965-96. American Journal of Preventive Medicine 2003; 25: 1-8.

28 Huang KS. Nutrient elasticities in a complete food demand system. American Journal of Agricultural Economics 1996; 78: $21-9$.

29 Anderson ES, Winett RA, Wojcik JR, Winett SG, Bowden T. A computerized social cognitive intervention for nutrition 
behavior: direct and mediated effects on fat, fiber, fruits, and vegetables, self-efficacy, and outcome expectations among food shoppers. Annals of Behavioral Medicine 2001; 23: 88-100.

30 Reidpath D, Burns C, Garrard J, Mahoney M, Townsend M. An ecological study of the relationship between social and environmental determinants of obesity. Health E Place 2002; 8: $141-5$.

31 Morland K, Wing S, Diez Roux A. The contextual effect of the local food environment on residents' diets: the atherosclerosis risk in communities study. American Journal of Public Health 2002; 92: 1761-7.

32 Morland K, Wing S, Diez Roux A, Poole C. Neighborhood characteristics associated with the location of food stores and food service places. American Journal of Preventive Medicine 2002; 22: 23-9.

33 Kubik MY, Lytle LA, Hannan PJ, Perry CL, Story M. The association of the school food environment with dietary behaviors of young adolescents. American Journal of Public Health 2003; 93: 1168-73

34 French SA, Stables G. Environmental interventions to promote vegetable and fruit consumption among youth in school settings. Preventive Medicine 2003; 37: 593-610.

35 Trost SG, Pate RR, Dowda M, Saunders R, Ward DS, Felton G. Gender differences in physical activity and determinants of physical activity in rural fifth grade children. Journal of School Health 1996; 66: 145-50.

36 Trost SG, Pate RR, Saunders R, Ward DS, Dowda M, Felton G. A prospective study of determinants of physical activity in rural fifth grade children. Preventive Medicine 1997; 26: $257-63$.

37 Sallis JF, McKenzie TL, Elder JP, Broyles SL, Nader PR. Factors parents use in selecting play spaces for young children. Archives of Pediatrics \& Adolescent Medicine 1997; 151: $414-7$.

38 Sallis JF, Prochaska JJ, Taylor WC. A review of correlates of physical activity of children and adolescents. Medicine and Science in Sports and Exercise 2000; 32: 963-75.

39 Dowda M, Ainsworth BE, Addy CL, Saunders R, Riner W. Environmental influences, physical activity, and weight status in 8- to 16-year olds. Archives of Pediatrics \& Adolescent Medicine 2001; 155: 711-7.

40 Bungum TJ, Vincent ML. Determinants of physical activity among female adolescents. American Journal of Preventive Medicine 1997; 13: 115-22.

41 Sundquist J, Malmstrom M, Johansson SE. Cardiovascular risk factors and the neighbourhood environment: a multilevel analysis. International Journal of Epidemiology 1999; 28: 841-5.

42 Yen IH, Kaplan GA. Poverty area residence and changes in physical activity level: evidence from the Alameda County Study. American Journal of Public Health 1998; 88: 1709-12.

43 Diez-Roux AV, Merkin SS, Hannan P, Jacobs D Jr, Kiefe C. Area characteristics, individual-level socioeconomic indicators, and smoking in young adults: the Coronary Artery Disease Risk Development in Young Adults Study. American Journal of Epidemiology 2003; 157: 315-26.

44 Ewing R, Schmid T, Killingsworth R, Zlot A, Raudenbush S. Relationship between urban sprawl and physical activity, obesity, and morbidity. American Journal of Health Promotion 2003; 18: 47-57.

45 Houston SL, Evenson KR, Bors P, Gizlice Z. Neighborhood environment, access to places for activity, and leisure-time physical activity in a diverse North Carolina population. American Journal of Health Promotion 2003; 18: 58-69.

46 Frank LD. Land use and transportation interaction: implications on public health and quality of life. Journal of Planned Education Research 2000; 20: 6-22.

47 Frank LD, Pivo G. Relationships Between Land Use and Travel Behavior in the Puget Sound Region. Final report to Washington State Transportation Center and Washington State Department of Transportation, Olympia, WA, 1998.

48 Ross C, Dunning A. Land Use Transportation Interaction: An Examination of the 1995 NPTS Data. Report No. FHWA-PL99-003. Washington, DC: Federal Highway Administration, 1997; 129-91.

49 Cervero R. Mixed land-uses and commuting: evidence from the American Housing Survey. Transportation Research 1996; A30: 361-77.

50 Frank LD, Pivo G. Impacts of mixed use and density on utilization of three modes of travel: single occupant vehicle, transit, and walking. Transportation Research Record 1994; 1466: $44-52$.

51 Cervero R, Kockelman K. Travel demand and the 3Ds: density, diversity, and design. Transportation Research 1997; D2: $199-219$.

52 Cervero R, Radisch C. Travel Choices in Pedestrian versus Automobile Oriented Neighborhoods. Working Paper 644. Berkeley, CA: University of California at Berkeley, Institute of Urban and Regional Development, 1995.

53 Frank LD, Stone B, Bachman W. Linking land use with household vehicle emissions in the central Puget Sound: methodological framework and findings. Transportation Research 2000; D5: 173-96. 